\title{
Doctor-reported hospital management of acute coronary syndrome in China: A nationwide survey of 1029 hospitals in 30 provinces
}

\author{
Yiping Chen ${ }^{1,2^{*}}$, Lixin Jiang ${ }^{2}$, Qiuli Zhang ${ }^{1}$, Xiaoshuai $\mathrm{Wei}^{2}, \mathrm{Xi} \mathrm{Li}^{2}$, Margaret Smith ${ }^{1}$, \\ Zhengming Chen ${ }^{1,2}$ \\ ${ }^{1}$ Clinical Trial Service Unit \& Epidemiological Studies Unit (CTSU), Nuffield Department of Clinical Medicine, University of Ox- \\ ford, Oxford, UK \\ ${ }^{2}$ China Oxford Centre for International Health Research, Fuwai Hospital, Chinese Academy of Medical Sciences, Beijing, China \\ Email: *yiping.chen@ctsu.ox.ac.uk
}

Received 5 March 2012; revised 5 April 2012; accepted 15 April 2012

\begin{abstract}
Background: Despite recent improvements in the hospital treatment of ACS, little is known about current cardiological practice in China or use of evidencebased approach in Chinese hospitals. Methods: A questionnaire about doctor-reported hospital management of ACS was posted to the head of the cardiology department of 1397 hospitals across 30 provinces of China. Reported use of various clinical procedures and treatments were analysed and compared between different types of hospital. Results: Of the $1029(74 \%)$ hospitals that responded, $43 \%$ were tier III (tertiary) hospitals. For STEMI, primary PCI was used as the main reperfusion therapy by $\mathbf{5 0 . 2} \%$ of tier III and $9.3 \%$ of tier II/I (secondary) hospitals. Most of hospitals also used various proven therapy routinely for STEMI and NSTEMI/UA, including antiplatelet therapy $(98 \%$ and $93 \%)$, anticoagulant $(96 \%$ and $90 \%)$, statin $(97 \%$ and $94 \%)$, oral $\beta$-blockers (87\% and $86 \%)$ and ACE-I (88\% and $83 \%)$. However, certain therapies with little or no proven value (eg, G.I.K., magnesium and Chinese tradition medicine) remained used routinely by $25 \%-40 \%$ of tier II/I hospitals. After discharge, statin, antiplatelet, $\beta$-blockers and ACE-I were reportedly used routinely by $85 \%-95 \%$ of the responders for secondary prevention. Conclusions: With a few exceptions, doctor-reported hospital management of ACS in China is largely consistent with that recommended by current guidelines. Large nationwide registries are needed to assess long-term adherence to treatments after hospital discharge.
\end{abstract}

Keywords: ACS; In-Hospital Treatments; Secondary

\footnotetext{
"Corresponding author.
}

Prevention; General Management; China

\section{INTRODUCTION}

During the past few decades the population mortality rate from cardiovascular disease has declined substantially in most developed countries, due partly to changes in risk factors and partly to improved treatment and medical care for patients [1-3]. However, in many developing countries such as China, the population mortality rates from acute coronary syndromes (ACS) and other related conditions are still increasing, probably reflecting mainly a corresponding increase in the population disease incidence [4]. In China, various proven treatments for ACS (e.g., statin, aspirin, clopidogrel, $\beta$-blocker, ACE-I) have become widely available, and there are national guidelines to facilitate implementation of evidence-based patient care [5-9]. Nevertheless, recent studies have documented large variations in management of ACS across different hospitals and regions of China, with substantial under-, over- and inappropriate treatments of many patients with ACS [10-14]. Several factors could contribute to the observed variations in clinical practice, including perceived benefits by doctors, provision of a health care system, side-effects related to a particular treatment and self-perceived risk and benefit by patients for certain treatments. In China, ACS managements in hospitals are largely determined by responsible cardiologists, so they are more sensitive to any emerging evidence from large trials or recommended changes in clinical guidelines. There is, however, little direct evidence of about current cardiological practice in China, in particular whether the clinical practice in China has been influenced by the evidence from large clinical trials compared to that $1-2$ decades years ago. We report here the results from a large nationwide survey of the doctor-reported hospital 
management of ACS in over 1000 hospitals across 30 regions of China, and compare them to the findings from a similar survey conducted over 10 years ago.

\section{METHODS}

A total of 1397 hospitals in 30 provinces and municipalities throughout China were invited to participate in a cross-sectional survey of current management of ACS during 2010. These hospitals were identified from various sources, including a hospital directory from the Chinese Society of Cardiovascular Medicine, previous collaborative networks and recommendations from colleagues. In China, all hospitals are classified into three main ranks: Tier III (tertiary) with more than 500 beds; Tier II (secondary) with 100 - 499 beds, Tier I (primary) with 20 - 99 beds and limited capacity. Since few ACS patients in China are treated in tier I (primary) hospitals the current survey involved mainly tertiary and secondary hospitals. A standard questionnaire, with a pre-addressed and postage-paid return envelope, was mailed to a named senior physician (usually the head of department) or, if this was unknown, to the unnamed head of the cardiology department in each hospital. In addition to personal and hospital information, the questionnaire covered a wide range of issues related to the general management of ACS in hospital (e.g., number of patients admitted, types and time delay of diagnostic tests, length of hospital stay), and to routine treatments given to ACS patients both in hospital and at discharge. Prior to the start of the main survey, the questionnaire was tested in 10 hospitals, after which minor modifications were made both to the questionnaire and to the survey procedures.

The survey took place from May to August in 2010. Non-responders were reminded with a letter and/or telephone call. Of the 1397 hospitals that were initially contacted, $1068(76 \%)$ responded by the end of August 2010. Of those, $39(3.6 \%)$ did not wish to complete the questionnaire or to be contacted further, leaving 1029 (74\%) with completed questionnaire data. Each returned questionnaire was checked, coded and then entered into the computer twice at the study coordinating centre in Beijing. Where the returned questionnaire was incomplete or there were inconsistencies, further queries were made directly to the responding doctor.

Differences in treatment and management of ACS patients between tertiary and secondary hospitals were tested, using the Pearson Chi square test for differences between proportions, and the Student t-test to compare means. All tests were two-sided, and those with $\mathrm{P}<0.05$ were considered to be statistically significant. SAS 9.2 was used for all analyses.

\section{RESULTS}

Overall, of the 1029 hospitals that responded with a completed questionnaire, $89 \%$ were from cardiology department. Of the responders, $89 \%$ were head of the department, $90 \%$ were consultants and $47 \%$ were interventional cardiologist. Of the 1029 hospitals surveyed, $446(43 \%)$ were tertiary hospitals and the remainder were secondary $(55 \%)$ or primary $(2 \%)$ hospitals. In the present report results from only $2 \%$ of primary hospitals were combined together with secondary hospitals. As expected, the tertiary hospitals were generally larger than the secondary hospitals (mean: 1080 hospital beds vs. 448; $\mathrm{P}<0.0001)$, and admitted more ACS patients annually (646 vs. $337 ; \mathrm{P}<0.0001)$. The percentages of tertiary hospitals having access to different treatments and facilities were also higher: Coronary Care Unit (CCU) $(93.5 \%$ vs. $76.7 \%$; P $<0.0001)$, catheter lab (90.4\% vs. $32.2 \%$; P $<0.0001)$, direct access to Percutaneous Coronary Intervention (PCI) $(67.5 \%$ vs. $18.0 \%$; $\mathrm{P}<0.0001)$, performing Coronary Artery Bypass Graft (CABG) (60.1\% vs. $5.1 \% ; \mathrm{P}<0.0001)$. The average length of hospital stay for ACS patients was marginally shorter in tertiary hospitals $(\mathrm{P}=0.03)$ (Table 1$)$. At admission, three main diagnostic tests for ACS (CK, CK-MB and troponin I/T) were reported from all types of hospital, and the testing results were usually available within 2 hours.

Of the ACS admissions annually, over a half were reported to involve unstable angina $(56 \%)$, with the proportion of STEMI and NSTEMI/UA being about 25\% and $18 \%$ respectively. A wide range of routine therapies for ACS for the first $24 \mathrm{hrs}$ following hospital admission were reported (Table 2). For STEMI, the routine use of reperfusion therapy, either by primary PCI or thrombolysis, was reported by $77.8 \%$ of all hospitals. Routine use of antiplatelet therapy (mainly dual antiplatelet therapy), statin, anticoagulant (mainly low molecular weight heparin), nitrates, oral $\beta$-blocker and ACE-I were also reported by most responders, both for STEMI and NSTEMI/UA patients. In addition, there was also moderate use of G.I.K. and magnesium (i.v.), with the reported proportion of routine use being about $20 \%$ - $30 \%$ for both STEMI and NSTEMI/UA. Although the routine use of i.v. $\beta$-blocker or calcium antagonists was relatively rare, selective use in responding hospitals was about $22 \%-47 \%$ (Table 2). Table 3 shows the proportions of hospitals reporting routine use of various treatments for ACS, by type of hospital. For STEMI, the percentage reporting routine use of any reperfusion therapy was significantly higher in tertiary than in secondary hospitals (82.1\% vs. $74.6 \%$; $\mathrm{P}=0.0004)$. Moreover, $20 \%$ more tertiary hospitals used primary PCI as the main reperfusion therapy (44.4\% vs. $21.3 \%$; $\mathrm{P}<0.0001)$, whereas the opposite was true for thrombolysis ( $45.1 \%$ vs. $68.4 \%$; $\mathrm{P}<0.0001)$. In addition, the percentage reporting a time of less than 3 hours for door-to-needle time for primary PCI was significantly higher in Tertiary hospitals (25\% vs. $16 \%$; 
Table 1. Hospital characteristics and routine management of ACS by type of hospital.

\begin{tabular}{|c|c|c|c|c|}
\hline \multirow{2}{*}{ Hospital characteristics } & All hospitals & Tertiary hospitals & Secondary hospitals & \multirow{2}{*}{$P$ value } \\
\hline & $(\mathrm{n}=1029)$ & $(\mathrm{n}=446)$ & $(\mathrm{n}=583)$ & \\
\hline Total no. of hospital beds & 721 & 1080 & 448 & $<0.0001$ \\
\hline No. of ACS admitted annually & 471 & 646 & 337 & $<0.0001$ \\
\hline$\%$ having $\mathrm{CCU}^{*}$ & 83.9 & 93.5 & 76.5 & $<0.0001$ \\
\hline$\%$ performing $\mathrm{CABG} \S$ & 29.0 & 60.1 & 5.1 & $<0.0001$ \\
\hline$\%$ having Catheter Lab & 57.4 & 90.4 & 32.2 & $<0.0001$ \\
\hline$\%$ having direct access to $\mathrm{PCI}+$ & 39.5 & 67.5 & 18.0 & $<0.0001$ \\
\hline$\%$ using primary PCI for STEMI & 27.0 & 50.2 & 9.3 & $<0.0001$ \\
\hline$\%$ using thrombolysis for STEMI & 59.7 & 30.0 & 82.3 & $<0.0001$ \\
\hline \multicolumn{5}{|l|}{$\%$ having various diagnostic tests } \\
\hline $\mathrm{CK}_{\dagger}^{\dagger}$ & 97.3 & 97.8 & 96.9 & NS \\
\hline CK-MB $\|$ & 97.6 & 99.6 & 96.1 & 0.0003 \\
\hline Troponins (I or T) & 86.8 & 94.7 & 80.8 & $<0.0001$ \\
\hline \multicolumn{5}{|c|}{$\%$ with average length of hospital stay for ACS } \\
\hline$<1$ week & 4.3 & 6.1 & 2.9 & \\
\hline 1 - 2 week & 83.3 & 83.0 & 83.5 & 0.03 \\
\hline$\geq 3$ week & 12.4 & 11.0 & 13.6 & \\
\hline Mean & & & & \\
\hline
\end{tabular}

*CCU: Coronary Care Unit; §CABG: Coronary Artery Bypass Graft; $₫$ PCI: Percutaneous Coronary Intervention; $†$ CK: Creatine Kinase; $\|$ CK-MB: Creatine phosphokinase MB isoenzyme.

Table 2. Reported use of emergency treatments for different types of ACS during the first 24 hours of hospital admission among 1029 hospitals.

\begin{tabular}{|c|c|c|c|c|c|c|}
\hline \multirow{3}{*}{ Treatments } & \multicolumn{3}{|c|}{ STEMI } & \multicolumn{3}{|c|}{ NSTEMI/UA } \\
\hline & $\begin{array}{l}\text { Routinely for } \\
\text { most patients }\end{array}$ & $\begin{array}{c}\text { Selectively for } \\
\text { some patients }\end{array}$ & $\begin{array}{l}\text { Rarely or never } \\
\text { used }\end{array}$ & $\begin{array}{l}\text { Routinely for } \\
\text { most patients }\end{array}$ & $\begin{array}{l}\text { Selectively for } \\
\text { some patients }\end{array}$ & $\begin{array}{c}\text { Rarely or } \\
\text { never used }\end{array}$ \\
\hline & $\%$ & $\%$ & $\%$ & $\%$ & $\%$ & $\%$ \\
\hline \multicolumn{7}{|l|}{ Frequently used } \\
\hline Any reperfusion therapy & 77.8 & 19.8 & 2.3 & - & - & - \\
\hline Thrombolysis & 58.3 & 32.7 & 9.0 & - & - & - \\
\hline Primary PCI* & 37.1 & 34.4 & 28.6 & - & - & - \\
\hline Any antiplatelet & 98.0 & 1.7 & 0.4 & 93.0 & 3.7 & 3.3 \\
\hline Aspirin plus clopidogrel & 85.7 & 10.1 & 4.2 & 78.8 & 13.1 & 8.1 \\
\hline Aspirin alone & 12.2 & 26.6 & 61.1 & 14.1 & 25.5 & 60.5 \\
\hline GP IIb/IIIa antagonist $\S$ & 4.1 & 30.9 & 65.0 & 3.4 & 25.4 & 71.2 \\
\hline Any anticoagulant & 95.5 & 3.7 & 0.8 & 90.2 & 5.3 & 4.5 \\
\hline LMWH & 93.5 & 4.7 & 1.8 & 88.7 & 5.6 & 5.6 \\
\hline $\mathrm{UFH}^{\dagger}+$ & 13.7 & 15.5 & 70.8 & 8.9 & 13.0 & 78.0 \\
\hline Statin & 97.0 & 2.1 & 0.9 & 93.7 & 2.9 & 3.4 \\
\hline Nitrates (oral or i.v.) & 87.9 & 10.7 & 1.4 & 85.2 & 10.7 & 4.1 \\
\hline Oral $\beta$-blocker & 87.6 & 11.1 & 1.4 & 85.7 & 10.7 & 4.1 \\
\hline ACE inhibitor & 86.7 & 12.4 & 0.9 & 83.4 & 12.3 & 4.3 \\
\hline \multicolumn{7}{|l|}{ Moderately used } \\
\hline G.I.K. $\|$ & 32.8 & 33.3 & 33.8 & 29.3 & 33.4 & 37.3 \\
\hline Magnesium (i.v.) & 20.9 & 32.5 & 46.6 & 19.1 & 30.3 & 50.5 \\
\hline \multicolumn{7}{|l|}{ Rarely used } \\
\hline Intravenous $\beta$-blocker & 10.9 & 25.3 & 63.8 & 9.2 & 22.0 & 68.8 \\
\hline $\mathrm{Ca}^{++}$antagonist & 8.0 & 44.3 & 47.7 & 9.9 & 47.4 & 42.7 \\
\hline Defibrase & 1.3 & 6.5 & 92.2 & 1.1 & 5.5 & 93.4 \\
\hline
\end{tabular}

*Restricted to hospitals with catheter lab; §GP IIb/IIIa antagonist: Glycoprotein IIb/IIIa antagonist; †LMWH: Low molecular weight heparin; †UFH: Unfractionated heparin; ||G.I.K.: Glucose Insulin potassium (K) infusion. 
Table 3. Reported routine use of various treatments during the first 24 hours of hospital admission for ACS by type of hospital.

\begin{tabular}{|c|c|c|c|c|c|c|}
\hline \multirow{3}{*}{ Treatments } & \multicolumn{3}{|c|}{ STEMI } & \multicolumn{3}{|c|}{ NSTEMI/UA } \\
\hline & $\begin{array}{l}\text { Tertiary hospitals } \\
\qquad(\mathrm{n}=446)\end{array}$ & $\begin{array}{l}\text { Secondary hospitals } \\
\qquad(\mathrm{n}=583)\end{array}$ & $P$ value & $\begin{array}{l}\text { Tertiary hospitals } \\
\qquad(\mathrm{n}=446)\end{array}$ & $\begin{array}{l}\text { Secondary hospitals } \\
\qquad(\mathrm{n}=583)\end{array}$ & $P$ value \\
\hline & $\%$ & $\%$ & & $\%$ & $\%$ & \\
\hline \multicolumn{7}{|l|}{ Frequently used } \\
\hline Any reperfusions therapy & 82.1 & 74.6 & 0.004 & - & - & - \\
\hline Thrombolysis & 45.1 & 68.4 & $<0.0001$ & - & - & - \\
\hline Primary PCI* & 44.4 & 21.3 & $<0.0001$ & - & - & - \\
\hline Any antiplatelet & 98.9 & 97.3 & NS & 93.5 & 92.6 & NS \\
\hline Aspirin plus clopidogrel & 94.6 & 78.9 & $<0.0001$ & 89.0 & 71.0 & $<0.0001$ \\
\hline Aspirin alone & 4.3 & 18.4 & $<0.0001$ & 4.3 & 21.6 & $<0.0001$ \\
\hline GP IIb/IIIa antagonist§ & 8.1 & 1.0 & $<0.0001$ & 6.3 & 1.2 & $<0.0001$ \\
\hline Any anticoagulant & 96.9 & 94.7 & NS & 91.9 & 88.9 & NS \\
\hline LMWH† & 94.2 & 93.0 & NS & 89.9 & 87.8 & NS \\
\hline $\mathrm{UFH}{ }_{\dagger}^{\dagger}$ & 15.2 & 12.5 & NS & 9.4 & 8.6 & NS \\
\hline Statin & 98.7 & 95.7 & 0.006 & 95.5 & 92.3 & 0.03 \\
\hline Nitrates (oral or i.v.) & 87.2 & 88.5 & NS & 84.8 & 85.6 & NS \\
\hline ACE inhibitor & 86.3 & 87.0 & NS & 84.1 & 82.8 & NS \\
\hline Oral $\beta$-blocker & 86.1 & 88.7 & NS & 85.2 & 85.2 & NS \\
\hline \multicolumn{7}{|l|}{ Moderately used } \\
\hline G.I.K.\| & 24.9 & 38.9 & $<0.0001$ & 21.7 & 35.0 & $<0.0001$ \\
\hline Magnesium & 14.8 & 25.6 & $<0.0001$ & 13.5 & 23.5 & $<0.0001$ \\
\hline \multicolumn{7}{|l|}{ Rarely used } \\
\hline Intravenous $\beta$-blocker & 7.8 & 13.2 & $<0.006$ & 7.2 & 10.8 & 0.046 \\
\hline $\mathrm{Ca}^{++}$antagonist & 7.4 & 8.4 & NS & 11.2 & 8.9 & NS \\
\hline Defibrase & 0.4 & 1.9 & 0.04 & 0.2 & 1.7 & 0.02 \\
\hline
\end{tabular}

*Restricted to hospitals with catheter lab; §GP IIb/IIIa antagonist: Glycoprotein IIb/IIIa antagonist; \$LMWH: Low molecular weight heparin; †UFH: Unfractionated heparin; ||G.I.K.: Glucose Insulin potassium (K) infusion.

$\mathrm{P}<0.03$; data not shown in Table 2). Routine use of dual antiplatelet therapy was significantly higher in the tertiary than in secondary hospitals, both for STEMI $(94.6 \%$ vs. $78.9 \%, \mathrm{P}<0.0001)$ and for NSTEMI/UA patients $(89 \%$ vs. $71 \%$; $\mathrm{P}<0.0001)$. There was no apparent difference between Tertiary and Secondary hospitals in percentages reporting the other frequently used treatments (Table 3).

The proportion of reported routine use of moderately (i.e., G.I.K. and i.v. magnesium) and rarely used treatments (i.e. i.v. $\beta$-blockers) was significantly higher in secondary than in tertiary hospitals, both for STEMI (G.I.K.: $38.9 \%$ vs. $24.9 \%$; magnesium: $25.6 \%$ vs. $14.8 \%$; i.v. $\beta$-blockers: $13.2 \%$ vs. $7.8 \%$ ) and NSTEMI/UA (G.I.K.: $35.0 \%$ vs. $21.7 \%$; magnesium: $23.5 \%$ vs. $13.5 \%$; i.v. $\beta$-blockers: $10.8 \%$ vs. $7.2 \%$ ) (Table 3). After the initial 24 hours of hospitalisation, there was little change in the overall patterns of treatments both for STEMI and NSTEMI/UA (data not shown), except that over a quarter of responders reported routine use of Traditional Chinese Medicine (TCM) in hospital and the percentage was about twice as high in secondary as in tertiary hospital ( $33 \%$ vs. $18 \% ; \mathrm{P}<0.0001$, data not shown in tables).

Several proven therapies were all reported as being in routine use for secondary prevention for ACS after hospital discharge, including statin (96.4\%), antiplatelet agent $(95.1 \%)$, oral $\beta$-blocker $(90.6 \%)$, ACE-I $(84.5 \%)$ and oral nitrate (59.4\%) (See Table 4). Angiotensin II antagonist $(26.0 \%)$, anticoagulant $(17.0 \%)$ and TCM $(14.9 \%)$ therapies were also used routinely but by a smaller percentage of hospitals. Other treatments such as calcium antagonist, diuretics and homocysteine, were used selectively by a high percentage of hospitals $(\sim 60 \%$ for calcium antagonist and diuretics). For most secondary prevention treatments, there were no substantial differences in reported routine use between tertiary and secondary hospitals (Table 5). Compared with secondary hospitals physicians at tertiary hospitals were more likely 
Table 4. Reported use of secondary prevention treatments for ACS patients after discharge in 1029 hospitals.

\begin{tabular}{|c|c|c|c|}
\hline Treatments & $\begin{array}{l}\text { Routinely for most patients } \\
\qquad \%\end{array}$ & $\begin{array}{l}\text { Selectively for some patients } \\
\qquad \%\end{array}$ & $\begin{array}{c}\text { Rarely or never used } \\
\%\end{array}$ \\
\hline \multicolumn{4}{|l|}{ Frequently used } \\
\hline Any lipid lowering & 96.4 & 2.8 & 0.8 \\
\hline Statin & 96.4 & 2.8 & 0.8 \\
\hline Other & 1.7 & 17.3 & 81.0 \\
\hline Any antiplatelet & 95.1 & 4.5 & 0.4 \\
\hline Aspirin plus clopidogrel & 49.8 & 41.6 & 8.6 \\
\hline Aspirin alone & 45.4 & 23.4 & 31.2 \\
\hline Oral $\beta$-blocker & 90.6 & 8.6 & 0.8 \\
\hline ACE inhibitor & 84.5 & 14.3 & 1.2 \\
\hline Oral nitrate & 59.4 & 35.1 & 5.5 \\
\hline \multicolumn{4}{|l|}{ Moderately used } \\
\hline Angiotensin II antagonist & 26.0 & 66.2 & 7.8 \\
\hline Anticoagulant & 17.0 & 9.7 & 73.3 \\
\hline $\mathrm{TCM}^{*}$ & 14.9 & 50.0 & 35.2 \\
\hline \multicolumn{4}{|l|}{ Rarely used } \\
\hline $\mathrm{Ca}^{++}$antagonist & 6.8 & 59.3 & 33.9 \\
\hline Diuretics & 2.4 & 64.3 & 33.2 \\
\hline Homocysteine lowering & 1.5 & 13.1 & 85.4 \\
\hline
\end{tabular}

*Traditional Chinese Medicine.

Table 5. Reported routine use of secondary prevention treatments for ACS patients by type of hospital.

\begin{tabular}{|c|c|c|c|}
\hline Treatments & $\begin{array}{l}\text { Tertiary hospitals } \\
\qquad(\mathrm{n}=446) \\
\%\end{array}$ & $\begin{array}{l}\text { Secondary hospitals } \\
\qquad \begin{array}{c}(\mathrm{n}=583) \\
\%\end{array}\end{array}$ & $P$ value \\
\hline \multicolumn{4}{|l|}{ Frequently used } \\
\hline Any lipid lowering & 98.2 & 95.0 & 0.007 \\
\hline Statin & 98.2 & 95.0 & 0.007 \\
\hline Other & 1.6 & 1.9 & NS \\
\hline Any antiplatelet & 95.5 & 94.9 & NS \\
\hline Aspirin plus clopidogrel & 62.8 & 39.8 & $<0.0001$ \\
\hline Aspirin alone & 32.7 & 55.1 & $<0.0001$ \\
\hline Oral $\beta$-blocker & 92.2 & 89.4 & NS \\
\hline ACE inhibitor & 85.2 & 84.0 & NS \\
\hline Oral nitrate agents & 54.3 & 63.3 & 0.0035 \\
\hline \multicolumn{4}{|l|}{ Moderately used } \\
\hline Angiotensin II antagonist & 30.3 & 22.8 & 0.007 \\
\hline Anticoagulant & 18.4 & 16.0 & NS \\
\hline $\mathrm{TCM}^{*}$ & 8.7 & 19.6 & $<0.0001$ \\
\hline \multicolumn{4}{|l|}{ Rarely used } \\
\hline $\mathrm{Ca}^{++}$antagonist & 6.7 & 6.9 & NS \\
\hline Diuretics & 1.6 & 3.1 & NS \\
\hline Homocysteine lowering & 1.1 & 1.7 & NS \\
\hline
\end{tabular}

*Traditional Chinese Medicine. 
to use dual antiplatelet therapy $(62.8 \%$ vs. $39.8 \%)$ and angiotensin II antagonist (30.3\% vs. $22.8 \%$ ), but less likely to use oral nitrate agents $(54.3 \%$ vs. $63.3 \%)$ and TCM (8.7\% vs. $19.6 \%)$.

Apart from secondary prevention treatments, the large majority of responders also strongly endorsed various lifestyle and primary preventive measures for ACS, including smoking cessation (99\%), physical exercise (93\%), dietary changes $(99 \%)$ and proper control of blood glucose (99\%), blood pressure (99\%) and blood lipid (99\%), with little difference between different types of hospitals (data not shown). However, the proportions who reported providing routine advice to ACS patients on prevention of depression and the flu vaccination was relatively low (61\% and 14\% respectively).

\section{DISCUSSION}

This is one of the largest surveys on the doctor-reported hospital management of ACS ever conducted in China. Although the survey did not involve a nationally representative sample, it included more than 1000 large and secondary sized hospitals from 30 regions in China, which are responsible for the care of most of ACS patients in the population. So the study findings should reflect to a large extent the current clinical practice on hospital treatments for ACS in China. The study showed that while a range of proven effective treatments for ACS were used routinely by most physicians, there was also significant inappropriate use of some treatments that have little or no proven value (e.g., G.I.K., magnesium, TCM), especially in secondary hospitals. Moreover, there was also significant under-use of certain effective treatments, especially dual antiplatelet therapy of aspirin plus clopidogrel.

The present survey provided information about what doctors say they do rather than what they may actually do in practice. Also, their views could be potentially biased as some of them have collaborated with us before on various trials, and also some respondents may give answers that are intended to please the researchers. Even replies made in good faith may be less accurate than a careful audit of actual practice. Nevertheless, the hospital treatments are largely dictated by doctors' decisions. The overall findings in the present study of doctor-reported hospital managements are highly compatible with those reported in a few registry studies of ACS in certain parts of China [15] and in large randomised trials of ACS [16-18]. In a prospective registry study of 2973 ACS patients from 51 large or specialised hospitals in 18 regions of China conducted in 2004-5 [15], 53\% of STEMI patients received primary $\mathrm{PCI}$ as the main reperfusion therapy, and the proportions who received antiplatelet therapy, $\beta$-blockers, ACE inhibitors and statin were also very high: $98 \%, 75 \%, 76 \%$ and $88 \%$ respectively [19].
Similarly, in a large randomised trial of 45,852 STEMI patients from 1250 hospitals in China during 1999-2005 [16-18], the proportions who received non-study related fibrinolytic therapy (within 12 hours of symptom onset), anticoagulant, ACE-I and nitrate were 65\%, 75\%, 68\%, and $94 \%$ respectively. In that trial, no data were available about use of statin, magnesium and G.I.K., but the use of diuretic and calcium antagonist was $23 \%$ and $12 \%$ respectively, which is compatible with the present study findings. The doctor-reported hospital management of ACS in China, at least in tertiary hospitals, is also consistent with that seen in many Western countries. For example, in the GRACE registry study of 12,666 unselected ACS patients from 94 European hospitals in 19992001 [20,21], 55\% of STEMI patients received primary PCI immediately after hospital admission, whereas the proportion who received antiplatelet therapy, $\beta$-blockers, ACE inhibitors and statin in hospital was 95\%, 81\%, $66 \%$ and $48 \%$ respectively. Since recommended use of statin in ACS was relatively recent, the relatively lower percentage of statin use in GRACE compared with the current survey may chiefly reflect the difference in time period when the surveys were done. However, despite widespread reported use of various proven effective treatments, the reported uses of a number of treatments shown previously by large randomised trials to have little or no net clinical benefits (such as G.I.K. and magnesium [22]) are also very high, especially those of secondary hospitals. Likewise, the reported use of Traditional Chinese Medicine (TCM) is also high especially in secondary-sized hospitals, despite the lack of reliable evidence from large randomised trials about their efficacy and safety. These survey findings reflect an empirical approach towards many existing treatments that have existed for many decades, even though an evidence-based approach towards management of ACS have also been adopted to a large extent in China over the last few decades.

One of the major changes in the doctor-reported hospital management of ACS in China over the last 10 - 15 years has been the rapid increase in the use of interventional procedures for ACS, driven probably partly by its improved efficacy compared with other treatments and partly by financial incentives. In 1996 only 51 hospitals in China were able to perform PCI for ACS [23], but ever since there has been a $40 \%$ annual increase in the number of cases performed. Consequently, the total number of PCI cases involving coronary stents has increased by almost 50-fold, from about 3000 cases in 1996 to about 145,000 in 2007 [23]. The present survey confirms this trend: about $90 \%$ of the relatively unselected tertiary hospitals have a catheter lab and 44\% also reported that primary PCI is used routinely for STEMI. The widespread use of primary PCI for STEMI has also resulted 
in the gradual decline in the use of fibrinolytic agents as main reperfusion therapy. In a similar survey conducted in 1998 of 1919 hospitals in China [24,25]), the use of thrombolysis as main reperfusion therapy for STEMI in tertiary hospitals was $42 \%$ compared with $30 \%$ in the present survey (Table 1). It is of interest that even in secondary hospitals about a third had now have a catheter lab despite recent policy by the health authority in China to restrict secondary hospitals from having a catheter lab because of capacity and safety concerns. The reported use of statin has also increased substantially during the same period, reflecting a significant impact of large randomised trials on clinical practice $[26,27]$. Likewise, the reported routine use of oral $\beta$-blocker has also doubled since late $1990 \mathrm{~s}$, from $43 \%$ in 1998 (Figure 1) to $88 \%$ in the present survey. Despite the reported use of oral $\beta$-blocker for ACS was very high, reported use of i.v. $\beta$-blocker as an emergency treatment for ACS is very limited $(7 \%)$, probably reflecting the impact of a recent large randomised trial conducted in China of the effect of early i.v. $\beta$-blocker for STEMI [18].

In agreement with various national and international guidelines for long-term secondary prevention of ACS, our survey also shows that several effective treatments were reportedly used routinely at discharge in most of the hospitals surveyed, including antiplatelet, $\beta$-blockers, ACE-I and statin. Compared with a similar survey in late 1990s, the increase in the reported use of statin has been most remarkable, from little in 1998 to almost universal use in the present survey (Figure 1). However, in our study no specific information was collected about the dose of statin used routinely, which tends to be smaller than those used in the West [14].

Although the short-term hospital emergency treatments are determined mainly by doctors, the long-term use of various secondary prevention treatments after discharge may be affected by various other factors, including provision of a health care system and reimbursement policy, side-effects related to a particular treatment, self-perceived risk and benefit by patients for certain treatments. The fact that many healthcare reimbursement policies in China only cover in-hospital treatments could be an important factor for non-adherence to long term use of several essential treatments. Although statin is widely prescribed at discharge by doctors, its long-term use among patients with ACS and other occlusive vascular conditions is low in China [12-14]. In a large survey of occlusive vascular patients, only $50 \%$ Chinese patients were on long-term statin therapy compared with $97 \%$ and $98 \%$ in the UK and Scandinavia countries (personal communication). A recent report from a Chinese registry study of ACS also found that despite routine use of effective treatments during hospital stay (e.g., 90\% aspirin, 70\% $\beta$-blockers and ACE-I inhibitors, and $80 \%$ statin), the combined use of these four treatments at discharge was only $48 \%$ and it dropped even further to $41 \%$ at one year after discharge [7]. The OASIS registry study of 2294 NSTEMI/UA patients in China recruited during 1999-2000 and followed up for 24 months also found the use of lipid lowering therapy was halved after 2-years of follow up [25]. There is evidence that despite increased investment by Chinese government, its share of total health expenditure has more than halved during the last two decades, from $36 \%$ in 1980 to $17 \%$ in 2004 [28]. Consequently, household payments for medical costs have more than doubled during the same period, from $22 \%$ to $54 \%$ of the total health expenditure [28]. Although doctors' knowledge and attitude play an important role, without proper provision of a more broad and affordable health insurance system,

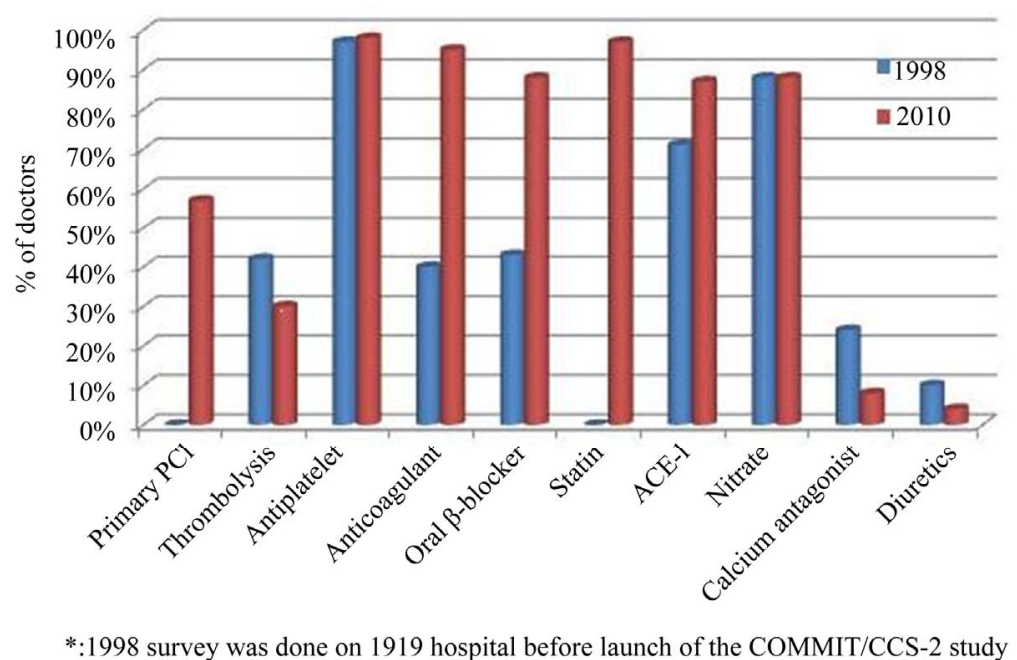

Figure 1. Comparison of the reported routine use of various in-hospital treatments for ACS by Chinese physicians between 1998* and 2010. 
hospital care and long-term management of ACS are unlikely to improve substantially for the majority of patients, as medical costs often exceed their financial capacity [28,29].

Despite the various limitations of the present study, it shows that there has been considerable improvement in doctor-reported general care of patients with ACS in China over the last two decades, and that the current patterns of doctor-reported hospital management for ACS in China, especially in tertiary hospitals, are largely compatible with that in most Western countries. However, there are striking differences between tertiary and secondary hospitals. As well as limited resources, one of the main reasons for the relatively higher proportion of inadequate management of ACS reported by doctors in secondary hospitals is the knowledge gap between evidence and practice as well as inappropriate incentives as part of China's fee-for-service payment system [30]. This is particularly important for China as limited resources could be wasted on many unnecessary and often ineffective treatments while use of the other effective treatments could be improved. Further education needs to be focused on raising awareness of evidence-based medicine in the secondary hospitals. To further reduce the "evidence-practice" gap, there is also a need for better delivery of proven therapy in a cost-effective and timely manner as well as for improved equality of access to the medical care for the general population. Establishment of a nationwide registry of ACS with periodical survey of hospital management of ACS, and of long-term secondary prevention after ACS, in a large and representative hospital sample is also urgently needed. This could help assess the quality of care and identify "evidencepractice" gaps so as to reinforce the evidence-based clinical practice in China.

\section{ACKNOWLEDGEMENTS}

The most important acknowledgment is to the doctors who participated in the survey and to many staff in CTSU and Fuwai hospitals who assisted with its undertaking. The survey was funded by a research grant from Novartis, but it was designed, conducted and analysed independently by the research groups in CTSU and Fuwai hospital. The UK Medical Research Council, the British Heart Foundation, and Cancer Research UK provided core funding to the CTSU. CTSU has a staff policy of not accepting honoraria or other payments from pharmaceutical industry, except for the reimbursement of costs to participate in scientific meetings.

\section{REFERENCES}

[1] Wijeysundera, H.C., Machado, M., Farahati, F., et al.
(2010) Association of temporal trends in risk factors and treatment uptake with coronary heart disease mortality, 1994-2005. Journal of the American Medical Association, 303, 1841-1847. doi:10.1001/jama.2010.580

[2] Capewell, S., MacIntyre, K., Stewart, S., et al. (2001) Age, sex, and social trends in out-of-hospital cardiac deaths in Scotland 1986-95: A retrospective cohort study. Lancet, 358, 1213-1217. doi:10.1016/S0140-6736(01)06343-7

[3] Ford, E.S., Ajani, U.A., Croft, J.B., et al. (2007) Explaining the decrease in U.S. deaths from coronary disease, 1980-2000. The New England Journal of Medicine, 356, 2388-2398. doi:10.1056/NEJMsa053935

[4] Wu, Z., Yao, C., Zhao, D., et al. (2001) Sino-MONICA project: A collaborative study on trends and determinants in cardiovascular diseases in China, Part I: Morbidity and mortality monitoring. Circulation, 103, 462-468. doi:10.1161/01.CIR.103.3.462

[5] Joint Committee for Developing Chinese Guidelines on Prevention and Treatment of Dyslipidemia in Adults (2007) Chinese guidelines on prevention and treatment of dyslipidemia in adults. Chinese Journal of Cardiology, 35, 390-419.

[6] Zhou, J.C., Zhao, H.C., Pan, K.H., et al. (2011) Current recognition and management of intra-abdominal hypertension and abdominal compartment syndrome among tertiary Chinese intensive care physicians. Journal of Zhejiang University SCIENCE B, 12, 156-162. doi:10.1631/jzus.B1000185

[7] Bi, Y., Gao, R., Patel, A., et al. (2009) Evidence-based medication use among Chinese patients with acute coronary syndromes at the time of hospital discharge and 1 year after hospitalization: Results from the Clinical Pathways for Acute Coronary Syndromes in China (CPACS) study. American Heart Journal, 157, 509e1-516e1.

[8] Liu, Q., Zhao, D., Liu, J., et al. (2009) Current clinical practice patterns and outcome for acute coronary syndromes in China: Results of BRIG project. Zhonghua Xin Xue Guan Bing Za Zhi, 37, 213-217.

[9] Song, X.T., Chen, Y.D., Pan, W.Q., et al. (2007) Gender based differences in patients with acute coronary syndrome: Findings from Chinese Registry of Acute Coronary Events (CRACE). Chinese Medical Journal (English Edition), 120, 1063-1067.

[10] Hu, D., Li, J. and Li, X. (2008) Investigation of blood lipid levels and statin interventions in outpatients with coronary heart disease in China: The China Cholesterol Education Program (CCEP). Circulation Journal, 72, 2040-2045. doi:10.1253/circj.CJ-08-0417

[11] Jiang, L., Armitage, J., Chen, Y., et al. (2010) Low use of statins among high-risk patients in China. World Heart Forum, 2010.

[12] Li, J., Jiang, L., Li, X., et al. (2010) Cross-sectional study of statin use among high-risk patients with coronary heart disease in China. Chinese Circulation Journal, 25, 348351.

[13] Jiang, L., Li, J., Feng, F., et al. (2010) Survey of statin usage in 4429 diabetic patients with atherosclerostic car- 
diovascular disease in China. Chinese Journal of Cardiovascular Medicine, 15, 264-268.

[14] Jiang, L.X., Li, X., Li, J., et al. (2010) A cross-sectional study on the use of statin among patients with atherosclerotic ischemic stroke in China. Chinese Medical Journal, 31, 925-928.

[15] Gao, R., Patel, A., Gao, W., et al. (2007) Prospective observational study of acute coronary syndromes in China: Practice patterns and outcomes. Heart, 94, 554-560. doi:10.1136/hrt.2007.119750

[16] COMMIT Collaborative Group (2000) Rationale, design and organization of the Second Chinese Cardiac Study (CCS-2): A randomized trial of clopidogrel plus aspirin, and of metertiaryrolol, among patients with suspected acute myocardial infarction. Journal of Cardiovascular Risk, 7, 435-441.

[17] COMMIT Collaborative Group (2005) Addition of clopidogrel to aspirin in 45,852 patients with acute myocardial infarction: Randomised placebo-controlled trial. Lancet, 366, 1607-1621. doi:10.1016/S0140-6736(05)67660-X

[18] COMMIT Collaborative Group (2005) Early intravenous then oral metertiaryrolol in 45,852 patients with acute myocardial infarction: Randomised placebo-controlled trial. Lancet, 366, 1622-1632. doi:10.1016/S0140-6736(05)67661-1

[19] Gao, R., Patel, A., Gao, W., et al. (2008) Prospective observational study of acute coronary syndromes in China: Practice patterns and outcomes. Heart, 94, 554560. doi:10.1136/hrt.2007.119750

[20] Fox, K.A., Goodman, S.G., Anderson, F.A. Jr., et al. (2003) From guidelines to clinical practice: The impact of hospital and geographical characteristics on temporal trends in the management of acute coronary syndromes. The Global Registry of Acute Coronary Events (GRACE). European Heart Journal, 24, 1414-1424. doi:10.1016/S0195-668X(03)00315-4

[21] Steg, P.G., Goldberg, R.J., Gore, J.M., et al. (2002) Baseline characteristics, management practices, and in-hos- pital outcomes of patients hospitalized with acute coronary syndromes in the Global Registry of Acute Coronary Events (GRACE). American Journal of Cardiology, 90, 358-363. doi:10.1016/S0002-9149(02)02489-X

[22] Mehta, S.R., Yusuf, S., Diaz, R., et al. (2005) Effect of glucose-insulin-potassium infusion on mortality in patients with acute ST-segment elevation myocardial infarction: The CREATE-ECLA randomized controlled trial. Journal of the American Medical Association, 293, 437 446. doi:10.1001/jama.293.4.437

[23] Gao, R. (2010) Current status of percutaneous coronary intervention in China. Heart, 96, 415-418. doi:10.1136/hrt.2009.170571

[24] Jiang, L.X., Chen, Z., Xie, J.X., et al. (2002) Survey of hospital management of myocardial infarction in China. Clinical Cardiology, 18, 3.

[25] Tan, H.Q., Zhu, J., Liang, Y., et al. (2005) Two year follow-up of acute ischemic syndrome without ST elevation. National Medical Journal of China, 85, 184-188.

[26] Group HPSC (2002) MRC/BHF Heart Protection Study of antioxidant vitamin supplementation in 20,536 highrisk individuals: A randomised placebo-controlled trial. Lancet, 360, 23-33. doi:10.1016/S0140-6736(02)09328-5

[27] Cannon, C.P., Braunwald, E., McCabe, C.H., et al. (2004) Intensive versus moderate lipid lowering with statins after acute coronary syndromes. The New England Journal of Medicine, 350, 1495-1504. doi:10.1056/NEJMoa040583

[28] Wang, H., Xu, T. and Xu, J. (2007) Factors contributing to high costs and inequality in China's health care system. Journal of the American Medical Association, 298, 19281930. doi:10.1001/jama.298.16.1928

[29] Jonathan, W. (2008) Chen Zhu: From barefoot doctor to China's Minister of Health. Lancet, 372, 1455.

[30] Yip, W., Hiso, W., Meng, Q., et al. (2010) Realignment of incentives for health-care providers in China. Lancet, 375, 1120-1130. doi:10.1016/S0140-6736(10)60063-3 